\title{
在中國猿人第一個頭蓋骨墢現 二十五周年紀念會上的報告
}

(1954年12月 27 日)

\section{郭 沫 若}

中國猿人北京種 (Sinanthropus pekinensis), 即所謂“北京人”，他的第一個頭蓋骨發現 於 1929 年 12 月 2 日，到今年是二十五周年了。

五十萬年前的化石人類的發現，在科學研究 上自然是很值得紀念的事。大家都知道，周口店 的發掘工作在解放前是在帝國主義勢力參加之下 進行的，而在今天巳經完全成篇了人民的科學事 業，逜是首先储得賀的事。

中國猿人化石地點的最初發現，我們不要忘

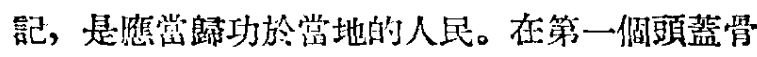
被發現之前也會縃發現過一些牙苳和頭高的碎 片，在 1927 年哞現了一個曰复，由性質上的鑑 定, 已經命名第“中國猿人北京種”，但到 1929 年 12 月 2 日，由裴文中同志發現了很完整的第 一佪頭蓋骨，這少集定了中國猿人在科學上的堅 實基礎。

周口店的初期發捉，由 1927 年起至 1937 年 日本帝國主義者發動了侵華戰爭篇止，一直不筧 中斷過。

根據不完全的統計，在中國猿人地點一共發 提了 1,873 天，共 178,965 個工作日，在北京 城 內進行研究和修理的工作人員還沒有包含在內。 在中國猿人地點, 㧥去約兩萬立方公尺的岩石和 砂土。在其他地點, 挖去了 4,200 立方公尺。像 這樣大規模的發掘，事實上是世界上空前未有 的。

這樣大規模的發掘的結果,一共探獲了 1,221 称一一約合 375 立方公尺的有待修理的標本。 單是在發現中國猿人的第一地點，自從第一個頭 藍骨發現以後，就絡續有大量的發現。中國猿人
化石連解放以來後期的發搝成果在內, 已 有 40 個上下的個體，包含 5储比較完整的頭 骨, 7 储 䫒骨磼片，2 個上顎骨，14 個下领骨，152 個 牙 因。有一些破碎的肢骨，1 偑鎖骨，3 個肱骨，1 㑬月骨，７偑股骨，1個陘骨。同時出土的文化 遺物, 有萑石器和經過人工打繁的石片和石塊, 一共有10萬多件，還有用火的證跡。其他還有兩 種植物化石, 118 種動物化石一一其中有 94 種哺 乳動物，哺乳動物中有 30 種是絕隇了。動物化 石的瞣富，有一部分是很夢人的，例如嗹骨鹿和 筮狗都各有 2,000 多话佰體。

關於人類化石，在今天所知道的材料，是以 南洋的爪哇猿人和我們的“北京人”第最古。雨者

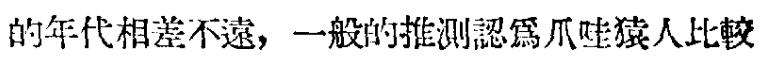

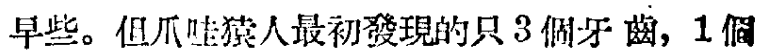

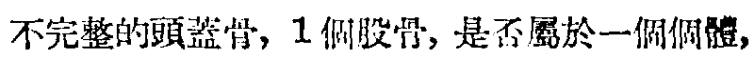
份然定論。踓然有少數的石器, 而末發現出用火 的登跡。其後受到周口店發掘的刺激，在 1929 年以後又會繼繼發掘, 得到 4 個頭骨, 也發現了 新人類的化石，但和周口店遗物的嘼富比敳起 來, 仍然是大有瓶色的。

在過去二十烧年中，周口店所發掘出的資 料, 由研究人只分別進行研究, 已出版發表單篇 論文的專册 72 種，共有 4,310 顼。一般性 的論 交和通俗性的文字還未計算在內。這些研究的 成果，踓然夾雜着不少的資本主義國家的學者的 工作在內，內容也少不了有大量的唯心論的馀 法，但由於材料的十分䆟富，䝿竟肯定了中國是 世界人類化石最啙富的地區。所有有關材料對於 進一步了解人類發展的榞史，㫪椎重物物的演化過
1 月號
科學通 報
- 7 . 
程, 以及第四紀地詹的地質, 悬定了一定的基 礎。

就人類發展來說, 中國猿人是由猿到人的一 個中間類型。同時發現的大批的舊石器和經過人 工打数的石片石塊以及用火的證跡，這些文化遺 物可以充分反胦中國猿人的生活情况。再從背生 的䇢多動物化石來考察, 我們更可以了解在五十 萬年前的中國猿人在生活中同䢙些動物和自然環 境, 是作過了怎樣的鞎苦的閏爭。人類就是通樣

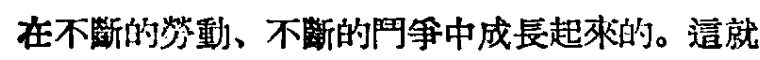

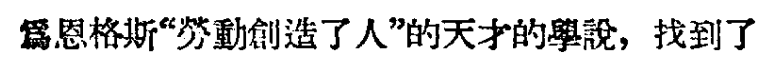
無此䨐富的證指。

通些害富的兾貴的材料，在過去日本帝國主

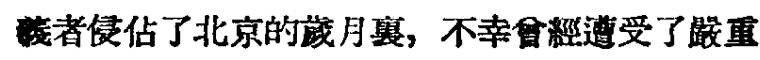
的摧毁。日本帝國主義者把當初在北京城內的研 究室佔搌了，用作特移機關，把大部分的化石和 其他重要的材料提毁了。㩲初步估計，除中國猿 人和江頁河人等材料外，其他標本約共椇失了 67 大箱，圆書設借等還不包含在內。周口店原有的 房屋也在那一時期遭受摧毁，在房山縣有三位工 作人員更拈受㭘殺，僈是使我們十分痛心的事。

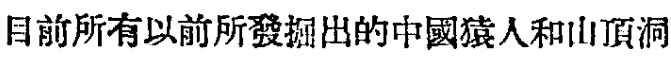
人的全部化石都已經雄蚈了中國。關於這件事 情, 美國的一部分人要促望任。那一大批珼貴資 料, 是由前協和繁學院的校長胡頓和 總務 長博 文，這兩位美國人在保管，在珍珠港事變後，是 在他們的手異严得下落不朋的。狺是全人類的賔 貫的文化逎限，我們相信全世界的人民和有道義

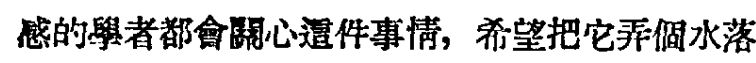
石出, 把原物歸還原處, 以便作更進一步的研 究。

就這樣，在解放前周口店的陪風一直是受着 帝國主義者的干預、把持、操縱、破壞，而終至

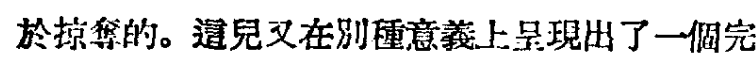
整的標本，那就是在解放前遭受首帝國主義文化 传略的中國科學研究工作本身的一個典型的化 石。

但是在中國共黨和毛主篎领学之下的中國 人民是站起來了。隨着中國人民革命的偉大勝 利，中国人民粉碎了牛殖民地命運的咖鈴，中國

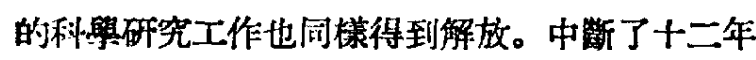
的周口店工作, 在 1949 年北京解放以後, 便立

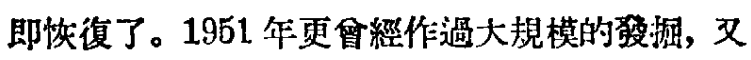

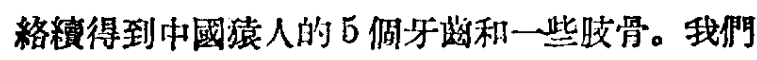
僄把摧毁了的山場整頓怢復了，重新培植了樹 木, 新建了辦公空、陳列室和招待室, 以迎接國 內外的寥觀者。由北京至周口店的公路已䋔测量 完果, 即將進行修建, 预計明年夏秋之交可以完 工。公路修成後, 這個世界知名的周口店——中 國猿人的故鄉, 必將成営北京近郊的遊覽的勝境 了。

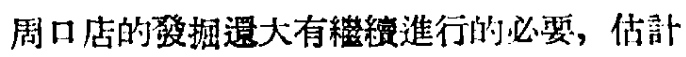
在土內埋藏的人類化石和其他文化遗品還很多, 還有更哣富的大量收權的可能。但由於新中國基 本建設事業大量的展開, 随侍随地都發现了地下

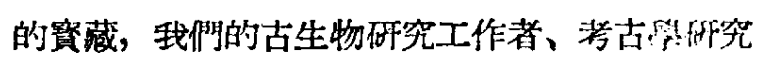

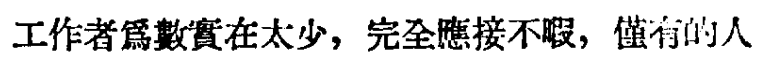
力䴇其他的任䅂所分散, 因而周口占的工作就不 能够集中力量來做。造在賞前,一面是可落的 事, 一面也是河惜的事。

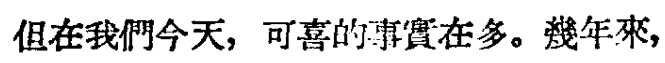

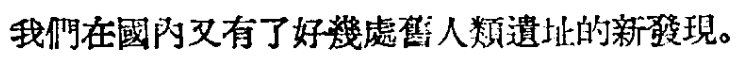
1952 年在成渝鐵路的修建工程㠷，在行川衍資隄

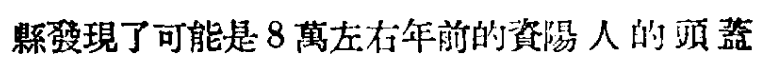
骨。今年六月, 在治淮工程中, 在安微省测洪䅫 也發現了比較新的嚄人㷋的化石。連些枌料都正: 在進行研究中. 特别值得注意的是最近在山西罪 浔縣的嚄石器文化遗址的發現。這项工作, 在令

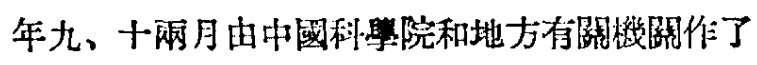
有系統的發掘，發現了 3 储人類牙这，雨千多倜 石器和經過人工打擊的石埧和石片, 25 程動物化

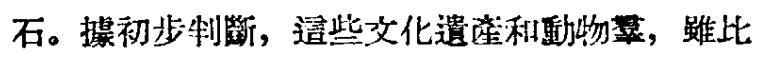
周口怎中國猿人年輕些，但大軆上是可以相比 的。那就是我們文發現了一㑚更新統中期約略三

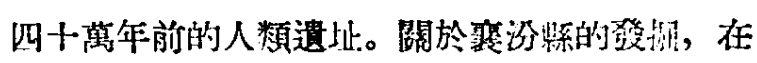
本次紀念會与將由㵅策坄同志作其題報等, 我在 這亭就不淮備多說了。

坐物如何起源, 如何㡎展, 以達到今天所有 的階段? 人類如何發生, 如何發展, 以達到今天 所有的階段? 遭些, 自人類有思想以来, 一直是 被注意的問題。历前全世界閣於這力面的材料遝 不很多, 前人研究的成果也很浱厚地带着資座階 秋唯心論的色彩, 要想得出畺正的科整的解答, 還有待於我們今後的努力。 
由二十五年來積累的事㛝來看, 特別由最近 五年來的事實隶看, 中國是人類化石與古人類文

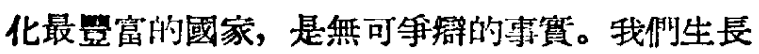
在這核好的環境裹面, 又生長在我們的思維活動 可以不受任何唯心論束紏的今天，我們應該怎樣 努力, 皘極克凟我椚的力量, 來勝任地担負起解 答問題的责任呢?

毫無疑問，我門歪該加緊學㚙狺證唯物主義 與歴史唯物主军，以馬克思列密主義來武裝我們 自己; 並烃力學刑蘇聯先進經驗，促進國際間的 自術交化的交流。

毫焎疑問, 我們隹該加緊唔養新生力量, 壯 大我們林學碉究工作者的隊伍, 加强圄結; 並努

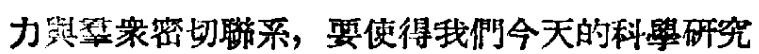

工作成䮡名䁈相符的人民科學。

毫無疑問，我們應該努力展開舉術上的自由 討論, 展開批評和自我批詐; 對於以前的研究應 該加以批制, 抛亲那些不正確的部分, 资産階級 唯心諭的錯誤的說法。

我們隻借把這一次中國猿人第一倜頭蓝衉發 現二十五周年紀念會作第新的任務的新的開始,

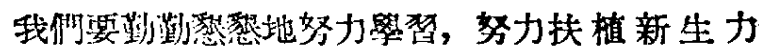
量, 决不騄傲自滿, 要好好做好工作。

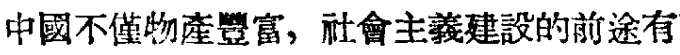
無限的光明;

中國的古脊椎動物乃至古人類化石在地下的 埋藏也非常豐富, 關於這一閏科的研究的前途 也是非常光明的。

\section{〔上接 94 頁〕}

我們塄找到有 41 項可能是關於新星或超 新星的 記载，並且其中有 11 偑可能對應於射電源，例 如:

1. “漢高帝三年七月有星孛於大角, 旬 餘乃 入。”（漢書和文磷通考）這比中外史上均有記载 的公元前 134 年出現於天蠍座的新㞗要早 70 年, 並且在史克洛夫斯基的“射電天文學”書中射電源 - 的分协圆上，大角 (即牧头座 $\boldsymbol{\alpha}$ 星) 附近有射電源 存在。(㯰段文字踓舁的是“星孛”(慧星), 但不言 移動，因此很可能是新星)。

2. “後漢永元十三年冬十一月乙丑軒轅第四 星間有小客星，色青黃。”（後漢書）畢渥特和倫 德瑪克等製新星星表時踓均將此段記 載列 篇 星, 但其估計的位置相差很遠, 應該是 101 年 12 月 30 日新星出現於天猫座 40 星附近。浸個新星 可能也是射電源。

3. “魏皇始元年( 396 年) 夏六月有星慧於管

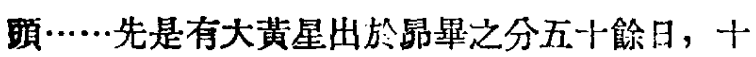
一月黃星又見，天下莫敵。”（魏害）遯顯然是顆 新星，因䈔（1）彗星不能不動地在一處倧留幾 個月; (2)新星的光度曲線往往是在極大之後, 裳其變暗到一定程度時, 又再弡筧一次（二次極
大), 然後才再腤下去。並且按其堂度來說, 很可 能是顆超新星。（這個新星在其他國家的歷史上無 記載)。

4. “秘太延三年正月王午有星晡前亘見東北， 在井左右，色黃大如橘。” (䅗書) 史克洛夫斯基 最近來信認爫造可能是 437 年 2 月 26 日超新星 出現於雙子座; 並且認第對還顆超新星有詳細考 証的必要, 因篇不久以前在雙子座率發現了一倜 大的射電源。但是, 關於這顆星, 除我們有管段 㓤载外，其他國家一無所知。

5. “宋涥熙八年六月己巳, 客星出金缩, 犯傳 舍星, 至朋年正月癸酉, 凡百八十有五日始隇。” (宋史和文獻通考)“金大定二十一年六月甲成, 客星見於華蓋，凡百五十有六日㙎。”（金史）這 兩段文字所記載的是一回事, 即 1181 年 8 月新星 出現於仙后座。史克洛夫斯基認篇對逼顆新星也 應加以詳細研究, 它在西方也無記載。

從新星的例子可以看出我們偉大祖國文化典 籍之豐富。我們如果將它加以科學整理, “取其精

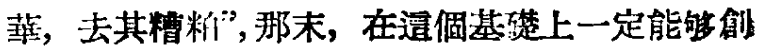
造出更多的和更新的東西桃。
1 月號
科學通報

- 9 • 